\title{
Subfossil lemur discoveries from the Beanka Protected Area in western Madagascar
}

David A. Burney ${ }^{\mathrm{a} *}$, Haingoson Andriamialison ${ }^{\mathrm{b}}$, Radosoa A. Andrianaivoarivelo ${ }^{\mathrm{c}}$, Steven Bourne ${ }^{\mathrm{d}}$, Brooke E. Crowley ${ }^{\mathrm{e}}$, Erik J. de Boer ${ }^{\mathrm{f}}$, Laurie R. Godfrey ${ }^{\mathrm{g}}$, Steven M. Goodman ${ }^{\mathrm{h}, 1}$, Christine Griffiths ${ }^{\mathrm{c}}$, Owen Griffiths ${ }^{\mathrm{c}, \mathrm{i}}$, Julian P. Humej, Walter G. Joyce ${ }^{\mathrm{k}}$, William L. Jungers ${ }^{1}$, Stephanie Marciniak ${ }^{\mathrm{m}}$, Gregory J. Middleton ${ }^{\mathrm{n}}$, Kathleen M. Muldoon ${ }^{\mathrm{o}}$, Eliette Noromalala ${ }^{\mathrm{b}}$, Ventura R. Pérez ${ }^{\mathrm{g}}$, George H. Perry ${ }^{\mathrm{m}}$, Roger Randalana ${ }^{\mathrm{c}}$, Henry T. Wright ${ }^{\mathrm{p}}$

${ }^{a}$ National Tropical Botanical Garden, 3530 Papalina Road, Kalaheo, Hawaii 96741, USA

${ }^{\mathrm{b}}$ Mention Anthropobiologie et Développement Durable, Domaine Sciences et Technologie, Université de Antananarivo, B.P. 906, Antananarivo 101,

${ }^{\mathrm{c} B i o d i v e r s i t y ~ C o n s e r v a t i o n ~ M a d a g a s c a r, ~ B . P . ~ 11028, ~ A n t a n a n a r i v o ~ 101, ~ M a d a g a s c a r ~}$

${ }^{\mathrm{d}}$ Naracoorte Lucindale Council, P.O. Box 2153, Naracoorte, Australia

${ }^{\mathrm{e} D}$ Departments of Geology and Anthropology, University of Cincinnati, Cincinnati, Ohio 45221, USA

${ }^{\mathrm{f}}$ Institute of Earth Sciences Jaume Almera (ICTJA-CSIC), Lluís Solé i Sabaris s/n, 08028 Barcelona, Spain

${ }^{\mathrm{g}}$ Department of Anthropology, University of Massachusetts-Amherst, 240 Hicks Way, Amherst, Massachusetts 01003, USA

${ }^{\text {h}}$ Field Museum of Natural History, 1400 South Lake Shore Drive, Chicago, Illinois 60605, USA

${ }^{\mathrm{i}}$ Australian Museum, 1 William St., Sydney, New South Wales 2010, Australia

${ }^{\mathrm{j}}$ Bird Group, Department of Life Sciences, Natural History Museum, Akeman Street, Tring HP23 6AP, United Kingdom

${ }^{\mathrm{k}}$ Department of Geosciences, University of Fribourg, 1700 Fribourg, Switzerland

${ }^{1}$ Association Vahatra, BP 3972, Antananarivo 101, Madagascar

${ }^{\mathrm{m}}$ Department of Anthropology, Pennsylvania State University, Old Main, State College, Pennsylvania 16801, USA

${ }^{\mathrm{n}}$ Sydney Speleological Society, Box 269, Sandy Bay, Tasmania 7006, Australia

${ }^{\circ}$ Department of Anatomy, College of Graduate Studies, Midwestern University, Glendale, Arizona 85308, USA

${ }^{\mathrm{p}}$ Museum of Anthropological Archaeology, University of Michigan, Ann Arbor, Michigan 48109, and Santa Fe Institute, 1399 Hyde Park Road, Santa Fe, New

*Corresponding author at: P.O. Box 36, Gloucester, North Carolina 28528, USA. E-mail address: dburney999@ gmail.com (D.A. Burney).

\begin{abstract}
A new fossil site in a previously unexplored part of western Madagascar (the Beanka Protected Area) has yielded remains of many recently extinct vertebrates, including giant lemurs (Babakotia radofilai, Palaeopropithecus kelyus, Pachylemur sp., and Archaeolemur edwardsi), carnivores (Cryptoprocta spelea), the aardvark-like Plesiorycteropus sp., and giant ground cuckoos (Соиа). Many of these represent considerable range extensions. Extant species that were extirpated from the region (e.g., Prolemur simus) are also present. Calibrated radiocarbon ages for 10 bones from extinct primates span the last three millennia. The largely undisturbed taphonomy of bone deposits supports the interpretation that many specimens fell in from a rock ledge above the entrance. Some primates and other mammals may have been prey items of avian predators, but human predation is also evident. Strontium isotope ratios $\left({ }^{87} \mathrm{Sr} /{ }^{86} \mathrm{Sr}\right)$ suggest that fossils were local to the area. Pottery sherds and bones of extinct and extant vertebrates with cut and chop marks indicate human activity in previous centuries. Scarcity of charcoal and human artifacts suggests only occasional visitation to the site by humans. The fossil assemblage from this site is unusual in that, while it contains many sloth lemurs, it lacks ratites, hippopotami, and crocodiles typical of nearly all other Holocene subfossil sites on Madagascar.
\end{abstract}

Keywords: Babakotia; Lemur extinction; ${ }^{14} \mathrm{C}$ dating; $\delta{ }^{13} \mathrm{C} ; \delta^{15} \mathrm{~N} ;{ }^{87} \mathrm{Sr} /{ }^{86} \mathrm{Sr}$; Biogeography

\section{INTRODUCTION}

The Beanka Protected Area of central western Madagascar, a remote area of dry forest on rugged limestone, offers an

Cite this article: Burney, D. A. et al 2020. Subfossil lemur discoveries from the Beanka Protected Area in western Madagascar. Quaternary Research 93, 187-203. https://doi.org/10.1017/qua.2019.54 opportunity to study newly discovered "subfossil" sites (i.e., sites containing unfossilized remains from recent millennia). These were previously unknown to the scientific world and largely undisturbed by local people or other human visitors. Precious finds of this sort provide special opportunities to study paleodistributions, extinction patterns, and paleoecological characteristics of extinct species as well as the living fauna. 
Beanka offers a wealth of untouched bone material lying on sheltered cave surfaces, as well as in situ stratigraphic contexts not excavated previously or otherwise disturbed by recent human activity. This in itself is important, because the rarest type of subfossil site on Madagascar is one that has not been previously disturbed by large-scale collection. Notable exceptions, such as parts of the Ankarana Massif in northern Madagascar (Simons et al., 1995) and Anjohikely in northwestern Madagascar (Burney et al., 1997), have offered possibilities for geochronological, taphonomic, and paleoecological analyses otherwise hampered in the majority of sites by the rapid and careless excavation and collection techniques typical of earlier centuries and decades.

The location of Beanka provides the opportunity to fill in gaps concerning the inferred ranges of extinct species in a large region previously understudied for extinct fauna characteristic of the late Holocene. Beanka is situated well north of the many subfossil sites of semiarid southwestern Madagascar and south of the mesic subfossil sites in the northwest. Only a few subfossils have been described from the nearby Bemaraha karst formation (Godfrey et al., 2004). With the new material from Beanka, it is now feasible to see whether the fauna of this previously unknown region is more similar to the mesic fossil sites of the northwest or the arid southwestern sites or whether it represents a combination of the two or a unique assemblage.

In addition, the extremely rugged and isolated nature of the Beanka region raises the possibility that some taxa that are believed to have gone extinct earlier (Burney et al., 2004; Crowley, 2010) might have survived significantly later in such a remote and virtually impenetrable landscape. Some extinction hypotheses for the demise of the island's megafauna would predict a mosaic-like pattern of extinction that would include pockets of late survival in habitat that was resistant to anthropogenic change - an example of "synergy" (Burney, 1999; Burney et al., 2003) or "subsistence shift" (Godfrey et al., 2019). In contrast, two hypotheses proposed for late prehistoric extinctions following human arrival, "blitzkrieg" (Martin, 1984) and "hypervirulent disease" (MacPhee and Marx, 1997), predict that extinction on a landmass following human arrival would proceed as a wave in the former case or break out everywhere simultaneously (in geologic time) in the latter (Burney et al., 2004). Hypotheses that invoke climate change as a major factor, such as VirahSawmy et al. (2010), do not make an explicit prediction regarding patterns of extinction over the landscape, but it would be reasonable to expect that areas with late survival would be somehow buffered against drought conditions.

In the last few years, protected area staff and scientific collaborators have systematically explored Beanka, discovering many caves and rock shelters containing promising materials for paleontological and archaeological studies. Here we report the first results from a richly fossiliferous cave, named by the discovery group as "Anjohingidrobe" (Giant Lemur Cave; hereafter AGB), and a small fissure or slot cave nearby that the group named "Anjohimaletsy" (Narrow Cave; hereafter AMT). By providing a description of the deposits, including positional and stratigraphic information, a preliminary radiocarbon chronology, and evaluation of preservation and paleoecological potential, we hope to provide some insight concerning environmental change and extinction dynamics as a backdrop to the late Holocene biodiversity crisis that is continuing and perhaps accelerating in Madagascar today. We also wish to set the stage for studies in progress, focusing on the details of chronology, biogeochemistry, systematics, and biogeography of an extensive area of Madagascar whose past was until now essentially unknown.

\section{LOCATION AND METHODS}

The Paysage Harmonieux Protégé de Beanka, a 17,100-ha protected area that was officially recognized on April 22, 2015, by a Malagasy government decree and is managed by Biodiversity Conservation Madagascar (BCM), is located ca. $350 \mathrm{~km}$ northwest of Antananarivo and $55 \mathrm{~km}$ east of Maintirano (Fig. 1). It is part of an extensive karst region (tsingy in Malagasy) that includes the Parc National de Bemaraha to the south, which is a UNESCO World Heritage site, and the remote Antsingimavo karst area to the north. The primary rock formation at Beanka is a Middle Jurassic limestone (Roig et al., 2012; Crowley and Sparks, 2018). Outcrops of Jurassic sandstone and shale are found along its eastern edge, and mid-Cretaceous sandstone, conglomerate, and shale flank its western edge. Within the limestone, rugged karst surface features, caves, narrow canyons, and subterranean rivers are covered in dense dry deciduous forest, thick with lianas, and more open woodlands. The nearly impenetrable nature of this landscape, combined with modern low human population densities, has resulted in limited anthropogenic pressure in this vast area, preserving natural habitats and endemic species and offering good potential for the discovery of caves containing previously untouched evidence for past life.

The Beanka area was briefly visited by speleologists in 1996, and the group returned in 2006 for a more detailed survey that revealed several interesting caves (Middleton, 2013). As in the adjacent karst areas, many caves are grikes, limestone features thought to have been formed by the solution of joints in the rock below the water table that subsequently opened to the surface (Veress et al., 2008).

Deep in the central part of the protected area is the Bokarano River, which itself flows underground through a winding cave passage for more than $1.6 \mathrm{~km}$. Near the river, but higher up the hillside, is a small nearly vertical cave (AGB) that is ideally configured to collect and preserve animal remains (Fig. 2). In 2009, BCM project manager Roger Randalana discovered the small opening and noted that many bones, some visibly larger than any of the living lemurs of the area, littered the surfaces inside. In subsequent years, AGB and a smaller fissure cave nearby (AMT) were inspected by several collaborating scientists, and plans were made, including procurement of the necessary permits, to mount an expedition primarily for the purpose of making surface bone 


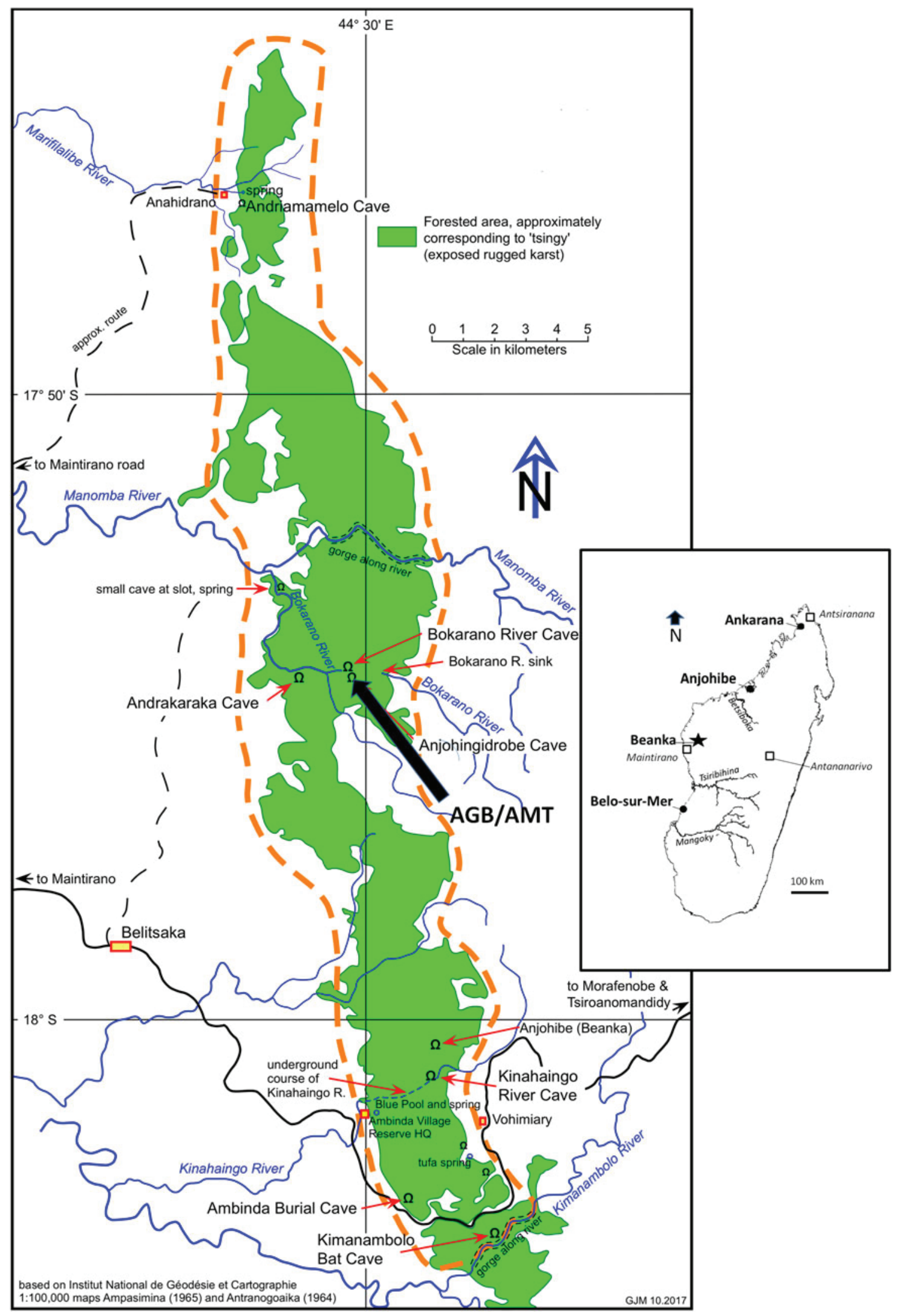

Figure 1. (color online) Large arrow indicates location of Anjohingidrobe Cave (AGB) near the center of the Beanka Protected Area in western Madagascar, at $17^{\circ} 54.35^{\prime} \mathrm{S}, 44^{\circ} 29.40^{\prime} \mathrm{E}$ (WGS 84) and $218 \mathrm{~m}$ above sea level. Anjohimaletsy (AMT) is a small fissure cave $80 \mathrm{~m}$ east of AGB. 


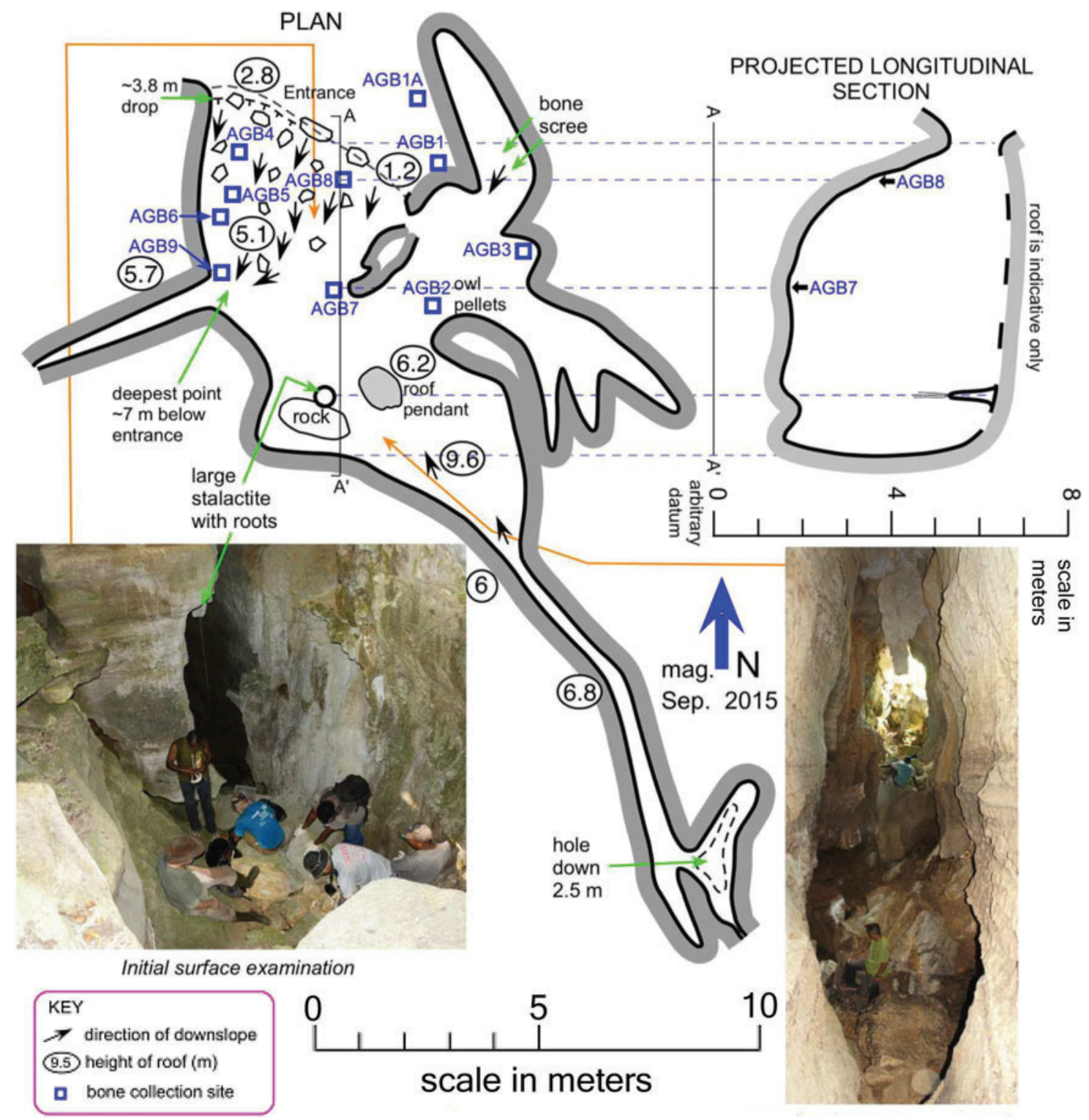

Figure 2. (color online) Plan map, vertical profile, and photographs of Anjohingidrobe Cave in the Beanka Protected Area. Surveyed by GJM with compass, inclinometer, and laser distance measure, September 21, 2013, and September 5, 2015.

collections, excavating test pits, and mapping the cave deposits. This work was conducted from September 5 to September 7 in 2015.

\section{Description of caves}

AGB has a single opening, facing northeast, about $5 \mathrm{~m}$ wide and varying from 1 to $3 \mathrm{~m}$ high, at $17^{\circ} 54.35^{\prime} \mathrm{S}, 44^{\circ} 29.40^{\prime} \mathrm{E}$ (WGS 84) and $218 \mathrm{~m}$ above sea level. Directly above the opening on the outside, there is a large rock ledge, $9.4 \mathrm{~m}$ above the top of the cave opening and greater than $1 \mathrm{~m}^{2}$ in area. Immediately inside the cave opening (Fig. 2), the floor drops $3.8 \mathrm{~m}$; large boulders form pockets inside at succeeding depths toward the back of the main chamber, where the ceiling is generally 6 to $9 \mathrm{~m}$ high and stalactites extend ca. $1 \mathrm{~m}$ from the ceiling. Rock shelves and scree slopes typify the east wall, and two small chambers end in soft clay sediment deposits. On the west wall, the boulder slope continues into the deepest point of the cave, $7 \mathrm{~m}$ below the entrance. A narrow passage at the rear (south) end of the cave continues upward to end at a small hole in the floor lacking sediment. On the outside, $3 \mathrm{~m}$ east of the entrance, a small indentation in the rock forms a dead-end passage containing clay sediments, and similar material continues back along the cave wall westward to the cave entrance.

\section{Sublocations within AGB}

Because the cave is predominantly vertical, with no large areas of horizontal or near-horizontal floor, it was necessary to distinguish bone accumulations in and near the cave by separate sublocation numbers, rather than a grid reference. These are noted in Figure 2, and Table 1 summarizes the characteristics of each sublocation. ABG-1 is the sediment layer 
Table 1. Characteristics of sublocations.

\begin{tabular}{lll}
\hline \hline Label & Location & Description \\
\hline AGB-1 & Outside cave entrance, east side & Mixture of limestone chips, boulders, and fine sediment \\
AGB-1A & 3 m east of ABG-1 & Fine to coarse sediments in small dead-end chamber \\
AGB-2 & East wall inside cave & Sloping ledge with owl pellet deposits \\
AGB-3 & Below east wall inside cave & Small dead-end chamber with fine sediment and bones \\
AGB-4 & Below entrance drop-off & Surficial bone scatter in pocket between boulders \\
AGB-5 & Downslope from AGB-4 & Surficial bone scatter in pocket between boulders \\
AGB-6 & Downslope from AGB-5 & Surficial bone scatter in pocket between boulders \\
AGB-7 & Farther inside near AGB-6 & Nearly level area with several small bone pockets A-E \\
AGB-8 & Below floor at drop-off & Small chamber below main floor level with sediments \\
ABG-9 & Downslope from AGB-6 & Deepest point of cave, with soft bone breccias \\
AMT & 80 m E of AGB entrance & Small slot cave with soft sediment and breccias. \\
\hline \hline
\end{tabular}

immediately east of the cave entrance. Where this rock wall enfolds to produce a small alcove, surface material and sediments were sublocated as AGB-1A. Proceeding into the main cave, a small ledge on the east wall inside is covered with a slope of fine debris (ABG-2). Directly below on the cave floor, a dead-end chamber descends farther under the east wall and is partially filled with soft clay sediment (AGB-3). Returning to the entrance, small pockets of bone-rich debris and sediment have accumulated at the base of the $3.8 \mathrm{~m}$ entrance drop, in a series of steps downward (AGB-4, AGB-5, and AGB-6). Immediately below AGB-5 and AGB-6 on the southward slope going back into the cave is a larger area of uneven topography, composed of large stones interspersed with bone-rich debris and sediment. This is the very productive sublocation AGB-7. Beneath the uneven floor of the cave near the entrance, there is a small chamber containing sediments with bones (AGB-8). On the opposite (west) wall of the cave, the cave floor descends to its lowest depth below the entrance at $-7 \mathrm{~m}$. There is a lag concentrate of darkly stained bones and fine limestone chips in this deepest pocket, in places lightly cemented into a breccia (AGB-9).

AMT, at $17^{\circ} 54.35^{\prime} \mathrm{S}, 44^{\circ} 29.41^{\prime} \mathrm{E}$, is a small fissure cave, or slot cave, about $80 \mathrm{~m}$ east of AGB, at approximately the same elevation. The entire floor comprises only about $1 \mathrm{~m}^{2}$ of sediment. At the back of the small cave is a narrow solution pit that descends another ca. $5 \mathrm{~m}$.

\section{Bone extraction}

At each sublocation inside AGB, the bone surface scatter was described and photographed with orientation and scale, and larger bones were then picked up individually and packed in labeled plastic bags or boxes. The smaller bones were placed in labeled containers along with all associated sediment and detritus and were removed from the cave for sifting. After removal of a layer of large bones and the associated fines down to ca. $10 \mathrm{~cm}$, the sublocation was rephotographed and all the remaining material taken out down to another $10 \mathrm{~cm}$ if that much was available. Most of these bone pockets, however, were very shallow, ending at bare rock in $10 \mathrm{~cm}$ or less.

\section{Excavation}

Two sublocations (AGB-3 and AGB-8) contained deeper sediments. AGB-3 was excavated in $10 \mathrm{~cm}$ levels down to rock at $50 \mathrm{~cm}$ in a ca. $1.0 \mathrm{~m}^{2}$ floor surface, and excavated sediment was carried outside for sifting. Excavation was undertaken with bare hands and small plastic tools, taking care to avoid contact that might damage the bones. AGB-8 was left intact for future research options. Only the visible remains on or within $10 \mathrm{~cm}$ of the surface were collected.

Outside the cave along the wall east of the entrance (AGB-1) and in the adjacent small chamber (AGB-1A), a mixture of boulders, limestone breakdown, and clay was excavated down to rock base. Sediments were removed in approximately $10-\mathrm{cm}$ levels, large bones were packed and labeled, and all fines were sifted. Small metal tools were used in the hard stony material.

At AMT, surface bones were collected and loose breccia was excavated to $50 \mathrm{~cm}$ depth from the narrow floor (with some careful use of metal tools to dislodge crusts). This material was disaggregated and sifted.

\section{Sifting and cataloging}

Fine material collected from the surface or excavated from deeper layers was dry-screened through mesh down to 3 $\mathrm{mm}$, and all biological materials were picked, sorted, and labeled. Each accessioned specimen container was labeled with sublocation and depth in sediment $(0 \mathrm{~cm}$ or $0-10 \mathrm{~cm}$ for materials on bare surface or embedded in surface material, respectively). In sublocation AGB-7, because of its uniformity and larger size compared with other sublocations, labels for individual pockets of bone received a letter subscript ( $A$ through $E$ ). The fossils were divided, accessioned, and cataloged by the Université d'Antananarivo (UA) and the Field Museum of Natural History (FMNH) in Chicago.

\section{Fossil analyses}

Sediment samples from AGB-1 and AGB-3 were processed for pollen and microscopic charcoal analysis at the University 